\title{
P223: The impact of reminder program on catheter-related blood stream infection rates in an intensive care unit in single center of korea
}

\author{
K-H Park' , OJ Choi ${ }^{1 *}$, HL Lee ${ }^{1}$, ES Shin ${ }^{1}$, GS Kim² ${ }^{2}$ IK Lee ${ }^{2}$, SI Jung ${ }^{3}, \mathrm{BH} \mathrm{Cho}^{4}, \mathrm{HB} \mathrm{Kim}^{5}$ \\ From 2nd International Conference on Prevention and Infection Control (ICPIC 2013) \\ Geneva, Switzerland. 25-28 June 2013
}

\section{Introduction}

catheter-related blood stream infection rates (CR-BSIs) are a substantial problem in the intensive care unit.

\section{Objectives}

To evaluate the impacts of reminder program of Medical staffs on the adherence to maximal barrier precautions (MBP), the duration of catheterization (days), and catheterrelated blood stream infection rates (CR-BSIs).

\section{Methods}

A simulated control group pretest-posttest design was used for this study. Data were collected from the medical intensive care unit of the $C$ university hospital in Gwangju, during two periods; Period 1 (from January, 2012 to April, 2012) served as the control group who did not received the reminder program, Period 2 (from June, 2012 to September, 2012) served as the experimental group who received the reminder program. The reminder program consisted of MBP adherence exhibit, short message service (adherence feedback to MBP, optimal recommendation, and hand washing), self-report checklist on central venous catheter management and questionnaire to the physicians about the utility of the central venous catheters $(\mathrm{CVC})$ in electronic medical records.

\section{Results}

The participants were 35 physicians who inserted central catheters, 17 nurses and 165 patients (control group 75, experimental group 90) with central catheter insertions for more than 48 hours. The adherence level of MBP was significally increased from $87.7 \%$ to $97.9 \%(\mathrm{p}=.026)$ after implementation of the reminder program. The duration of cathetherization was significally decreased in Period 2 compared Period 1 (from 10.6 to 7.4 days, $\mathrm{p}=.024$ ). The density incidence of CR-BSI rate was significally decreased in Period 2 compared Period 1 (3.7 to 1.5/1,000 catheterdays, Relative risk $2.51 ; 95 \%$ confidence interval 2.33 2.69, $\mathrm{p}<.001)$.

\section{Conclusion}

Reminder Program on Catheter-Related Blood Stream Infection Rates for patients with CVC in an Intensive Care Unit was effective in improving the adherence level of MBP and decreasing the duration of catheterization and CR-BSI rate.

\section{Disclosure of interest}

None declared.

\section{Author details}

${ }^{1}$ Office for Infection Control, Chonnam National University Hospital, Gwangju, Korea, Republic Of. ${ }^{2}$ Medical Intensive Care Unit, Chonnam National University Hospital, Gwang-ju, Korea, Republic Of. ${ }^{3}$ Departments of Infectious Diseases, Chonnam National University Hospital, Gwang-ju, Korea, Republic Of. ${ }^{4}$ Department of Nursing Graduate School, Chonnam National University Hospital, Gwang-ju, Korea, Republic Of. ${ }^{5}$ Departments of Infectious Diseases, 2Seoul National University Hosptia, Seoul, Korea, Republic Of.

Published: 20 June 2013

doi:10.1186/2047-2994-2-S1-P223

Cite this article as: Park et al:: P223: The impact of reminder program on catheter-related blood stream infection rates in an intensive care unit in single center of korea. Antimicrobial Resistance and Infection Control 2013 2(Suppl 1):P223.

'Office for Infection Control, Chonnam National University Hospital, Gwang-

ju, Korea, Republic Of

Full list of author information is available at the end of the article

( ) 2013 Park et al; licensee BioMed Central Ltd. This is an Open Access article distributed under the terms of the Creative Commons Attribution License (http://creativecommons.org/licenses/by/2.0), which permits unrestricted use, distribution, and reproduction in any medium, provided the original work is properly cited. 